\title{
KINETICS OF PHENOL AND BENZOATE BIODEGRADATION IN STATIC CULTIVATION SYSTEM BY Burkholderia cepacia
} G4.

Shalaby, M. E. A.

Agricultural Botany Department, Agric. Microbiology, Fac. of Agric., Kafr El-Sheikh Univ., Egypt.

\begin{abstract}
Kinetics of phenol and benzoate degradation by Burkholderia cepacia G4 in classical batch mode of static culture were investigated over a wide range of initial substrate concentrations applied as single substrates. Due to better adaptation to changing conditions, faster degradation of both phenol and benzoate was observed when higher concentrations were used. The results show decrease of the biomass yield coefficient, $Y_{X / S}$, from 0.83 to $0.31 \mathrm{~g} \mathrm{~g}^{-1}$ when the initial phenol concentration was increased from 0.54 to $0.73 \mathrm{~g} \mathrm{~L}^{-1}$, supporting the well known inhibitory effect of phenol. On the other hand, linear increasing of the yield coefficient was observed with increasing benzoate concentration. During all experiments, maximum specific substrate consumption rates, rsmax, were reached to $0.27 \mathrm{~g} \mathrm{~g}^{-1} \mathrm{~h}^{-1}$ for phenol and to $0.40 \mathrm{~g} \mathrm{~g} \mathrm{~g}^{-1} \mathrm{~h}^{-1}$ when benzoate was the sole source of carbon in the bioreactor. In the present study, minor inhibitory effect of benzoate was observed during their investigated concentration range.

To explain their degradation modelling, experimental data of both phenol and benzoate biodegradation were fitted using various kinetic models. The results demonstrated that the Yano and Koga equation gave the best fit, compared with the other models. It means that biodegradation of phenol and benzoate can be described by the same kinetic model. Based on the kinetic data, all experiments were not sensitive to change in the saturation constant, $\mathrm{K}_{s}$; therefore, $\mathrm{K}_{\mathrm{s}}$-value was fixed at 0.042 and $0.068 \mathrm{~g} \mathrm{~L}^{-1}$ for phenol and benzoate, respectively. After that, $\mathrm{rsmax}$ and the inhibition constant, $\mathrm{K}_{\mathrm{i}}$, parameters were re-fitted in all experiments. In general, the kinetic parameters of both phenol and benzoate degradation were influenced by the initial substrate and bacterial cell mass concentrations, in addition to adaptation with changing in the culture conditions.
\end{abstract}

\section{INTRODUCTION}

Organic pollutants are widespread compounds produced in relatively high concentrations in many agricultural and industrial activities. Pesticides play an important role in plant protection, but contaminate our environment, and efficient treatment methods are necessary to reduce their concentration in wastewater to acceptable levels. Metabolites of these compounds are, maybe, more toxic than the parent compound (Amoros et al. 2000). Biological treatment, therefore, is the most effective technique, because it has the potential to degrade these contaminates with innocuous end products and minimum secondary waste generation (Goudar et al. 2000). Phenol and benzoate are among compounds that result from agricultural and industrial effluents causing environmental pollution. The widespread use of both compounds in various applications has led to extensive soil and wastewater toxicity. Phenol is a toxic and hazardous substance even at low 
concentrations (Babish and Davis, 1984 and Li and Humphrey, 1989). Biodegradation of phenol, therefore, has long been the subject of numerous investigations using a wide variety of microorganisms (Cho et al. 2000 and Léonard et al. 1999). Benzoate is considerably less toxic compound released into the environment through routine disposal in waste treatment facilities (Hamzah and Al-Baharna, 1994). Biodegradation of benzoate was also investigated by Hickey and Focht (1990) and Van der Woude et al. (1995).

Burkholderia cepacia G4 (formerly: Pseudomonas cepacia G4) is one of the most effective bacterial strains that have the ability to use a wide range of the environmental pollutants. This strain is capable of mineralizing several aromatic compounds, like phenols, toluol, cresols and benzoic acid, with relatively high conversion rates (Nelson et al. 1987). The degraded strain has also used for phenol degradation as a sole source of carbon via unstable steady states in continous culture by Schröder et al. (1997). Degradation of phenol and benzoate was also studied in a fluidized-bed reactor using the same strain (Hecht et al. 2000). Phenol and benzoate are typically broken down via the meta-cleavage pathway (Farell and Quilty, 1999), and catechol is the main intermediate produced in this way. Induction of meta- cleavage was stated by Mörsen and Rehm (1990) for phenol and by Harayama et al. (1987) for benzoate degradation. Accumulation of intermediates during degradation of phenol and benzoate was commonly observed by Allsop et al. (1993).

Information about the kinetics of phenol and benzoate biodegradation is necessary for optimal design and operation of biological treatment systems. Based on the growth limitation, Monod kinetics was the more suitable model to describe benzoate biodegradation (Ampe and Lindley, 1996). For phenol, their inhibitory nature is well known, and a variety of substrate inhibition models have been used to describe its kinetics. The wellknown Haldane equation for enzymes has been used extensively to describe phenol degradation (D'Adamo et al. 1984 and Goudar et al. 2000). On the other hand, Schrö der et al. (1997), who compared the fitting of kinetic data for phenol degradation by Burkholderia cepacia G4, derived from unstable steady states, to various kinetic equations, found the best fitting for the equation of Yano and Koga, (1969).

The aim of the present work is to investigate degradation of phenol and benzoate individually by a pure culture of Burkholderia cepacia G4 under conditions as exist in the environment. Therefore, classical batch was the suitable cultivation technique chosen to guarantee reproducible and fitness initial biomass concentration. This work aims also to detect if degradation of phenol and benzoate via the same pathway (meta-clavage), can be described by the same kinetic model.

\section{MATERIALS AND METHODS}

\section{Microorganism:}

Burkholderia cepacia G4 (Nelson et al. 1986) was kindly obtained from K. N. Timmis (Division of Microbiology, GBF, Braunschweig, Germany). For 
the biomass composition, an average value for Pseudomonas given by Roels (1983), was assumed to be $\mathrm{CH}_{1.79} \mathrm{O}_{0.50} \mathrm{~N}_{0.20}$. The ash content was considered as $7.5 \%$.

\section{Chemicals:}

Phenol (synthesis grade) was purchased from Merck (Darmstadt, Germany). All other chemicals used were of the highest purity commercially available.

3. Media:

The microorganism was cultivated in a mineral salt medium containing per liter deionized water: $100 \mathrm{~mL}$ buffer solution, $1.3 \mathrm{~mL}$ trace elements solution, $0.7 \mathrm{~mL}$ solution $\mathrm{A}$ and $4 \mathrm{~mL}$ solution $\mathrm{B}$. The buffer solution consisted of (in grams per liter): $\mathrm{Na}_{2} \mathrm{HPO}_{4} .2 \mathrm{H}_{2} \mathrm{O}, 87.8 ; \mathrm{KH}_{2} \mathrm{PO}_{4}, 30.0$; and $\left(\mathrm{NH}_{4}\right) 2 \mathrm{SO}_{4}$, 12.37. Trace elements solution (in grams per liter) contained: $\mathrm{MgO}, 10.75$; $\mathrm{CaCO}_{3}, 2.0 ; \mathrm{FeSO}_{4}$. $7 \mathrm{H}_{2} \mathrm{O}, 4.5 ; \mathrm{ZnSO}_{4}$. $7 \mathrm{H}_{2} \mathrm{O}, 1.44 ; \mathrm{MnSO}_{4}$. $2 \mathrm{H}_{2} \mathrm{O}, 0.87$ $\mathrm{CuSO}_{4} .5 \mathrm{H}_{2} \mathrm{O}, 0.25 ; \mathrm{CoSO}_{4} .7 \mathrm{H}_{2} \mathrm{O}, 0.28 ; \mathrm{H}_{3} \mathrm{BO}_{3} .7 \mathrm{H}_{2} \mathrm{O}, 0.06$; and $\mathrm{HCl}$ (conc.), $51.3 \mathrm{~mL}$. Solution A was $246.48 \mathrm{~g} \mathrm{~L}^{-1} \mathrm{MgSO}_{4}$. $7 \mathrm{H}_{2} \mathrm{O}$, and solution $\mathrm{B}$ was $3.20 \mathrm{~g} \mathrm{~L}^{-1} \mathrm{FeSO}_{4}$. $7 \mathrm{H}_{2} \mathrm{O}$, and $9.45 \mathrm{~g} \mathrm{~L}^{-1}$ ethylene diamine tetraacetic acid (EDTA). The medium was prepared by autoclaving water and buffer solutions. The trace elements solution and the solutions A and B were filter sterilized and added aseptically to the autoclaved part after cooling to prevent precipitation.

\section{Analytical methods:}

Ten-milliliter samples were taken from the reactor and centrifuged for $15 \mathrm{~min}$ at $15000 \mathrm{rpm}(24652 \mathrm{~g})$ at a temperature of $15^{\circ} \mathrm{C}$ (Biofuge Stratos, Heraeus instruments, Kendro Hanau, Germany) in stainless steel tubes. The pellets were dried at $60^{\circ} \mathrm{C}$ for $48 \mathrm{~h}$ in a vacuum (VT 6025, vacutherm, Kendro, Henau, Germany), and weighed after cooling for biomass estimation. The supernatants were filtered (Rezist 30/0.2 $\mu \mathrm{m}$, Schleicher and Schüll, Dassel, Germany) and stored at $-20 \stackrel{\circ}{ } \mathrm{C}$ for subsequent analysis. Phenol was quantified by using HPLC (Biotronik UV-Detector BT 3030) using a reversedphase column (Nucleosil 120-3C 18 (721721.46); front column (721606.40)). The mobile phase was methanol and water (6:4) and the flow was set at $1 \mathrm{~mL}$ min. ${ }^{-1}$. Phenol was detected at $270 \mathrm{~nm}$. For benzoate, HPLC (Jasco, UV-970) (intelligent UV/VIS Detector) with a reverse phase column (Chromasil 100$5 \mathrm{C}_{8}$ (728043.40); front column (728057.40) Chromcart was used. The mobile phase gradient composed from $\mathrm{K}_{3} \mathrm{PO}_{4} \cdot \mathrm{H}_{2} \mathrm{O}$, water and methanol and the flow was also set at $1 \mathrm{~mL} \mathrm{min.} .^{-1}$. Benzoate was detected at $210 \mathrm{~nm}$.

\section{Cultivations:}

As classical batch, cultivations of phenol and benzoate were individually carried out. Prior to the batch experiment, a studied substrate was added to the reactor through a sterile filter (Rezist 30/0.2 $\mu \mathrm{m}$, Schleicher \& Schüll, Dassel, Germany) by a syringe via a membrane seals part. After the added substrate was completely used, the next batch can be started out. All cultivations were carried out in a steam sterilizable $3.5 \mathrm{~L}$ stirred tank bioreactor (FZ 2000, Chemap AG, Volketswil, Switzerland). The working volume was $2.52 \mathrm{~L}$. The reactor was equipped with a console for regulation of temperature, $\mathrm{pH}$ value, and agitation. The $\mathrm{pH}$ and the dissolved oxygen 
Shalaby, M. E. A.

content were measured by heat autoclavable calibrated electrodes (Ingold, Urdorf, Switzerland).

All cultivations were carried out at $25^{\circ} \mathrm{C}$. The $\mathrm{pH}$ was maintained at 7.0 by automatic addition of $1.0 \mathrm{~mol} \mathrm{~L}^{-1}$ sodium hydroxide solution and $0.5 \mathrm{~mol} \mathrm{~L}^{-1}$ sulfuric acid solutions. The $\mathrm{pH}$ values were checked routinely during cultivation by sampling. Aeration was done with compressed air at a flow at $162 \mathrm{~L} \mathrm{~h}^{-1}$ (STP) by using a mass flow controller (PR-3000, MKS, Germany). The inlet gas was sterilized with membrane filter and the stirrer speed was adjusted at $300 \mathrm{rpm}$. The exhaust gas analyzer, all probes, balances and pumps were connected with the bioprocess control computer type UBICON (Universal Bioprocess Control System) (ESD, Hanover, Germany) for data acquisition and control strategies of the reactor.

\section{Kinetic models:}

Based on a material balance for substrate in the batch cultivation, specific substrate consumption rate can be expressed as:

$$
\mathrm{rs}=\mathrm{dCs} /(\mathrm{dt} \mathrm{Cx})=\mu / \mathrm{Yx} / \mathrm{s}
$$

To describe the relationship between the maximum specific substrate consumption rate and concentration of non inhibitory substrate on a limitation growth, Monod (1949) proposed the following equation:

$$
r s=r s \max C s /(K s+C s)
$$

To describe the growth kinetics of the inhibitory substrates, different kinetic models, were used. Substrate inhibition is most often expressed by the Andrews equation (Andrews, 1968) (equal to the Haldane equation of enzyme kinetics):

$$
r_{s}=r_{s} \max C_{s} /\left(K_{s}+C_{s}+C_{s}{ }^{2} / K_{i}\right)
$$

There are also several other equations describing substrate inhibition kinetics, some of them derived from Monod equation (Wayman and Tseng, 1976), some not (Tan et al. 1996). A very versatile equation for substrate inhibition was proposed by Yano and Koga (1969):

$$
r_{s}=r_{S} \max C_{s} /\left(K_{s}+C_{s}+C_{s} \sum_{J=1}^{p}\left(C_{s} / K_{i j}\right)^{j}\right.
$$

Here, the information of inactive enzyme-substrate complex with more than two substrate molecules is considered. The Andrews or Haldane equation is obtained by $\mathrm{j}=1$. The Yano and Koga equation was used by Schröder et al. (1997). Yano and Koga model for $p=2$ is a four parameter equation. Due to the very low values, the inhibition constant $\left(\mathrm{Cs}^{2} / \mathrm{K}_{\mathrm{i} 1}\right)$ was negligible compared with $\mathrm{Cs}_{s} 3 / \mathrm{K}_{\mathrm{i}}{ }^{2}$. The four-parameter equation can therefore be reduced to a three-parameter equation without reducing the quality of the fit [Yano and Koga 2] as follows:

$$
r_{s}=r_{s} \max C_{s} /\left(K_{s}+C_{s}+\left(C_{s}{ }^{3} / K_{i 2}{ }^{2}\right)\right)
$$

The inhibitory models containing four-parameters of Luong (1987),

$$
r s=r s \max C s\left(1-C_{s} / C_{s}^{*}\right)^{n} /\left(K_{s}+C s\right)
$$

and containing five-parameters of Han and Levenspiel (1988) were also compared as follow:

$$
r s=r s \max C s\left(1-C_{s} / C_{s}^{*}\right)^{n} /\left(C_{s}+K_{s}\left(1-C_{s} / C_{s}^{*}\right)^{m}\right)
$$




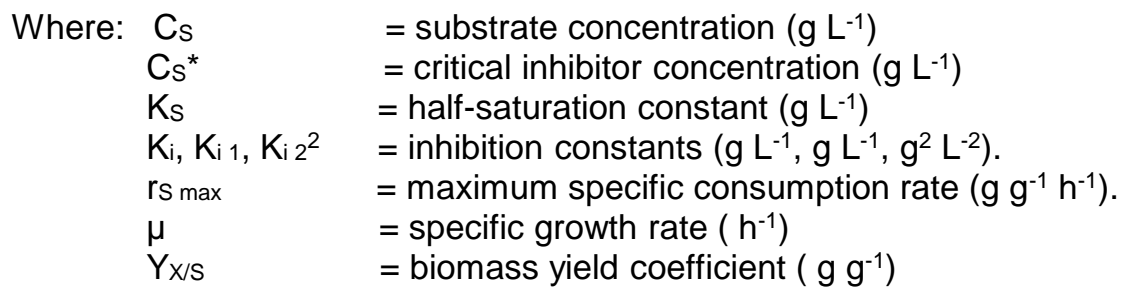

\section{RESULTS AND DISCUSSION}

\section{Biodegradation of phenol and benzoate}

All experiments were carried out as "classical batches" to guarantee fitness initial biomass concentrations, compared to adjusted batch cultivations. As sole source of carbon, degradation of phenol and benzoate via Burkholderia cepacia G4 was individually investigated. For each substrate, three batch experiments were carried out using different initial substrate concentrations. For phenol, initial substrate concentration, Cso, starting biomass, $\mathrm{C}_{\mathrm{x} 0}$, degrading time, as well as biomass yield coefficient are given in Table 1.

Table 1. Experimental data for phenol degradation by B. cepacia G4 in classical batch cultivations.

\begin{tabular}{|l|c|c|c|c|}
\hline Experiments & $\begin{array}{c}\mathbf{C s}_{\text {so }} \\
\mathbf{g ~ L}^{-1}\end{array}$ & $\begin{array}{c}\mathbf{C}_{\mathbf{x} 0} \\
\mathbf{g ~ L}^{-1}\end{array}$ & $\begin{array}{c}\text { Time } \\
\mathbf{h}\end{array}$ & $\begin{array}{c}\mathbf{Y} \mathbf{x} / \mathbf{s} \\
\mathbf{g ~ g}^{-1}\end{array}$ \\
\hline Phen-1 & 0.50 & 1.83 & 4.53 & 0.61 \\
\hline Phen-2 & 0.54 & 2.06 & 4.53 & 0.83 \\
\hline Phen-3 & 0.73 & 1.57 & 2.02 & 0.31 \\
\hline
\end{tabular}

The first run (Phen-1) was started when $0.50 \mathrm{~g} \mathrm{~L}^{-1}$ phenol was added to the reactor. After $4.53 \mathrm{~h}$, the substrate was completely consumed. The biomass increased from $1.83 \mathrm{~g} \mathrm{~L}^{-1}$ to $2.14 \mathrm{~g} \mathrm{~L}^{-1}$ during these time periods which correspond to a yield of $0.61 \mathrm{~g} \mathrm{~g}^{-1}$. Due to further increase in the biomass concentration to $2.17 \mathrm{~g} \mathrm{~L}^{-1}$, the yield reached $0.68 \mathrm{~g} \mathrm{~g}^{-1}$, which is considerably lower when compared with the chemostat data recorded by Schröder et al. (1997). The second and the third runs (Phen-2 and Phen-3) were carried out with initial phenol concentrations of 0.54 and $0.73 \mathrm{~g} \mathrm{~L}^{-1}$ which was completely consumed after 4.53 and $2.02 \mathrm{~h}$, respectively. The overall biomass yield reached $0.83 \mathrm{~g} \mathrm{~g}^{-1}$ in Phen-2, but decreased to $0.31 \mathrm{~g} \mathrm{~g}$ 1 in the third run. It means that, the lowest yield resulting in higher initial phenol concentration in Phen-3, indicating growth inhibition. This is in accordance with the observations of Babish and Davis (1984) and Li and Humphrey (1989), who stated that the inhibitory effect of phenol can be occurre even at low concentrations. In Fig. 1, the time courses for phenol biodegradation of the three batches are compared. 
Shalaby, M. E. A.

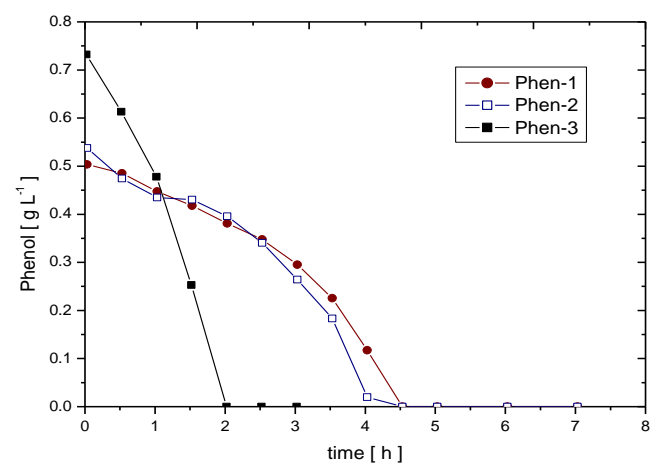

Fig. 1. Time courses for phenol biodegradation of the investigated batches.

It shows faster degradation of phenol in Phen-3 compared with the other runs, indicating better adaptation of the cell performance on the excess substrate concentration. So, the cells were adapted well to a higher consumption rate in this batch. There seems to be an influence of the initial phenol concentration. These results, therefore, are more in conjunction with the theory of Kovárová-Kovar and Egli (1998), who assumed that cell performance is influenced by adaptation and its training to the higher substrate concentration. This is also represented when specific phenol conversion rates of the three batches were plotted (not shown) as a function of phenol concentration. Maximum specific phenol consumption rate, r $_{S m a x}$, was, then estimated as $10 \mathrm{~g} \mathrm{~g}^{-1} \mathrm{~h}^{-1}$ for both first and second runs, but reached to $0.27 \mathrm{~g} \mathrm{~g}^{-1} \mathrm{~h}^{-1}$ in the third batch.

A correlation between amount of phenol dose and its degradation rate was studied by Vojta et al. (2002). The authors observed that the decrease of the degradation rate resulted in increasing of phenol concentration in addition to other effects. It means that, $0.73 \mathrm{~g} \mathrm{~L}^{-1}$ phenol was not enough to inhibit its degradation rate. On the other hand, the experimental data are in accordance with Jayakumar and Lim (1989), who observed increasing in phenol degradation rate by Methylomonas mucosa in the inhibitory branch with increasing its concentration. Decreasing of the biomass yield observed in Phen-3 is perhaps due to other factors such as accumulation of intermediates in the reactor. This is, in agreement with the findings of Wang and Loh (1999), who suggested that accumulation of intermediates is one of the factors that inhibited the conversion rate. In the inhibitory branch, growth of Methylomonas strain L3 was influenced by high concentrations of accumulated toxic formaldehyde, which is reported to be inhibitory for cell production of L3 strain (DiBiaso et al. 1981).

For benzoate, three batch experiments were also carried out as described for phenol using different initial benzoate concentrations. Table 2 shows the data for the three experiments. 
Table 2. Experimental data for benzoate degradation by B. cepacia G4 in classical batch cultivations.

\begin{tabular}{|l|c|c|c|c|}
\hline Experiments & $\begin{array}{c}\mathbf{C s}_{\mathbf{s}} \\
\mathbf{g ~ L}^{-1}\end{array}$ & $\begin{array}{c}\mathbf{C}_{\mathbf{x}} \\
\mathbf{g ~ L}^{-1}\end{array}$ & $\begin{array}{c}\text { Time } \\
\mathbf{h}\end{array}$ & $\begin{array}{c}\mathbf{Y} \text { x/s } \\
\mathbf{g ~ g}^{-1}\end{array}$ \\
\hline Benz-1 & 0.73 & 0.48 & 4.92 & 0.16 \\
\hline Benz-2 & 0.98 & 0.77 & 4.70 & 0.24 \\
\hline Benz-3 & 1.30 & 1.64 & 3.03 & 0.37 \\
\hline
\end{tabular}

To compare its degradation with phenol, $0.73 \mathrm{~g} \mathrm{~L}^{-1}$ benzoate, similar used in Phen-3, was used with the first batch (Benz-1). Due to its minor inhibitory effect, benzoate was completely converted after $4.92 \mathrm{~h}$, considerably slower than phenol, resulting in a biomass yield of $0.16 \mathrm{~g} \mathrm{~g}^{-1}$. So, the degrading strain needs longer time to prepare adaptive enzymes for mineralizing the new substrate. In the second run (Benz-2), $0.98 \mathrm{~g} \mathrm{~L}^{-1}$ benzoate is completely used after $4.70 \mathrm{~h}$ from starting, resulting in a biomass yield of $0.24 \mathrm{~g} \mathrm{~g}^{-1}$. In Benz-3, the initial biomass is higher because the cells in the previous batches were better adapted. Here, $1.30 \mathrm{~g} \mathrm{~L}^{-1}$ benzoates are only consumed in $3.03 \mathrm{~h}$, considerably faster than in the previous runs. The overall biomass yield reached $0.37 \mathrm{~g} \mathrm{~g}^{-1}$ in this run. Time courses of the three runs for benzoate biodegradation were compared in Fig. 2 .

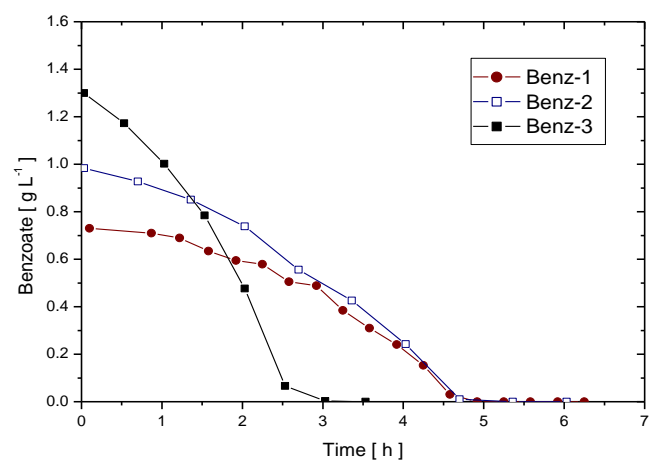

Fig. 2. Time courses for benzoate biodegradation of the investigated batches.

As for phenol, the batch performed out of the highest initial substrate concentration shows a deviation to the other runs, is considered faster conversion. So, the results of benzoate experiments, as for phenol, are more in conjunction with the theory of Kovárová-Kovar and Egli (1998). It is interesting, as for phenol, to mention that the use of a higher initial concentration of benzoate leads to higher maximum specific degradation rate. Based on the results plotted in Fig. 3, the cell mass yield coefficient $\left(Y_{x / S}\right)$ was influenced by the initial substrate concentration. 
Shalaby, M. E. A.

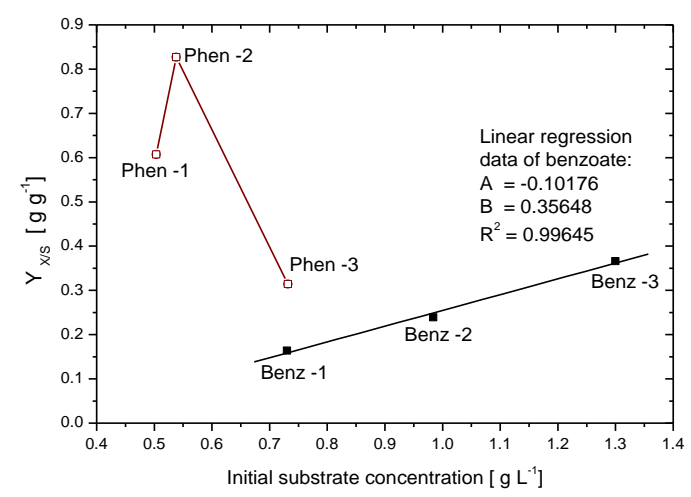

Fig. 3. Influence of the initial substrate concentration on the yield coefficient of all batch runs for phenol and benzoate biodegradation.

For phenol, the biomass yield increased when the initial phenol concentration reached to $0.54 \mathrm{~g} \mathrm{~L}^{-1}$ in Phen-2, after that, the yield sharply decreased, resulting in higher initial substrate concentration in the third batch. As can be seen, the biomass yield varied between 0.83 and $0.31 \mathrm{~g} \mathrm{~g}^{-1}$ when the initial phenol concentration ranged from 0.54 to $0.73 \mathrm{~g} \mathrm{~L}^{-1}$. Wang and Loh (1999) found that the mass yield coefficient ranged between 0.94 and $0.43 \mathrm{~g}$ $\mathrm{g}^{-1}$ when the initial phenol concentration varied from 0.25 to $0.80 \mathrm{~g} \mathrm{~L}^{-1}$ under batch conditions. It indicates that the inhibitory influence of phenol was done within the experimental concentration range.

On the other hand, linear increase of the $Y_{x / S}$ values corresponding to the initial benzoate concentration was obtained, and an excellent regression degree of $R^{2}$ was found to be larger than 0.996 . This, however, may reflect the overall non-, or at least, less inhibitory effect of benzoate concentration during the studied concentration range. The inhibitory effect of benzoate against Pseudomonas putida ATCC 49451 at higher initial concentration was also stated by Loh and Chua (2002). The inhibitory effect of benzoate was also observed on the growth of $E$. coli (Salmond et al. 1984).

\section{Modeling in kinetics of phenol and benzoate biodegradation:}

To establish a kinetic model valid for both phenol and benzoate degradation by $B$. cepacia G4 subjected to different substrate concentrations under classical batch conditions, the experimental data were fitted to different models. For this purpose, the nonlinear least squares fitting routine of MicroCal's ORIGIN ${ }^{\circledR}$ software package was used. All experiments were firstly fitted with investigated models, and then one batch of both substrates was selected for their specific consumption rate versus substrate concentration in Fig.4. The fitted functions for Yano and Koga, Haldane, Luong and Han \& Levenspiel are plotted with the experimental data of phenol degradation in Fig. 4a. Due to very low regression degree, Luong's model was avoided for benzoate degradation. To examine wether benzoate degradation can be described by the substrate limitation kinetics, Monod model was compared with the other models and plotted in Fig. 4b. The low data scatter allows a clear differentiation between the fitted models. 

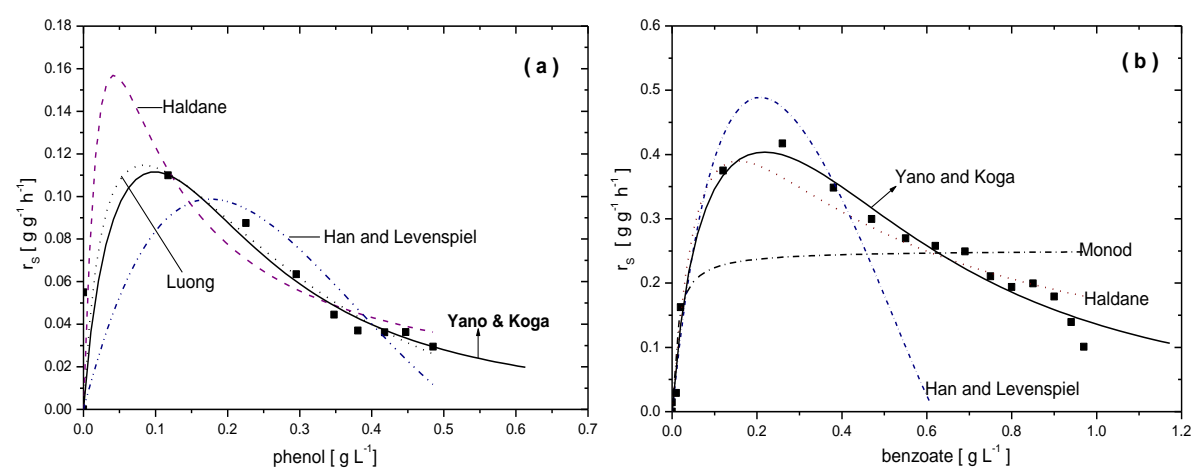

Fig. 4. Specific substrate consumption rate, $r_{s}$, versus substrate concentration with different kinetic models for phenol (a) and benzoate (b) batch cultivations.

The results show that, the Yano and Koga model, which is based on multiple inactive enzyme-substrate complexes, provides excellent data regression degrees for both phenol and benzoate degradation under classical batch conditions. This is in accordance with observations of Schröder et al. (1997), who compared the fitting of kinetic data for phenol degradation by Burkholderia cepacia G4 to various kinetic equations, found the best fitting for the equation of Yano and Koga (1969).

The extension to the four parameters of Luong (1987) model as well as to the five parameters of Han and Levenspiel (1988) did not result in a better fit. Additionally, poorest fit of all the tested equations was achieved for the Haldane model, which is most commonly used to describe substrate inhibition. This, however, is in contrary to the findings of Andrews (1968), D'Adamo et al. (1984) and Goudar et al. (2000), who well described phenol degradation by Haldane equation. Wang and Loh (1999) found that, the Haldane equation was not sufficient for modelling phenol degradation profile. For benzoate, poorst fit with very low regression was obtained when Monod equation was compared. Despite its inhibitory effect, the results are on contrary to Ampe and Lindley (1996), who described the kinetic parameters of Alcaligenes eutrophus 335 on low and high concentrations by using Monod equation.

For phenol, the lower bound of the fitting algorithm was set to 0.042 ; the estimated $\mathrm{Ks}_{\mathrm{s}}$-values are around this value. Due to their unsensitivity to a variation of $\mathrm{Ks}_{\mathrm{s}}$-value, $\mathrm{K}_{\mathrm{s}}$ was fixed at $0.042 \mathrm{~g} \mathrm{~L}^{-1}$. For phenol, specific substrate consumption rates, with the better model simulation of Yano and Koga after fixing of $\mathrm{K}_{\mathrm{s}}$-value, versus phenol concentration are re-plotted in Fig. 5. For benzoate, $\mathrm{Ks}_{\mathrm{s}}$ value was also fixed, but at $0.068 \mathrm{~g} \mathrm{~L}^{-1}$. The resulting rsmax-values and the fitting quality ( $R^{2}$-values) for all phenol and benzoate cultivations are given in Table 3 . 
Shalaby, M. E. A.

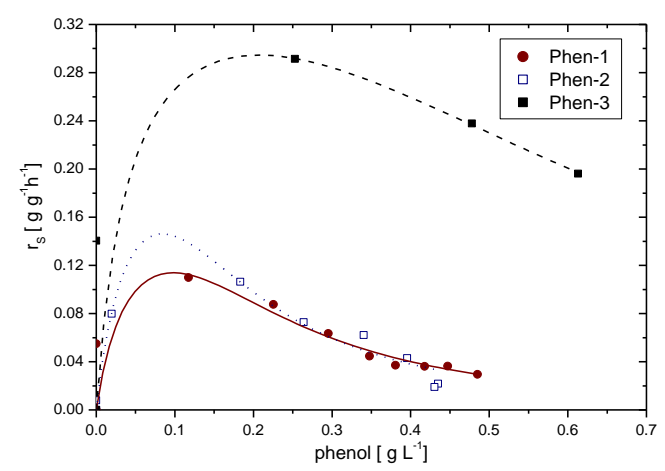

Fig. 5.Specific phenol consumption rates, $r_{s}$, (symbols) and their simulation by using Yano and Koga model after fixing of $\mathrm{K}_{\mathrm{s}^{-}}$ value (lines) versus phenol concentration for all batches.

Table 3. Fitting of all experimental data for phenol and benzoate biodegradation by Yano and Koga model after fixing of $\mathrm{K}_{\mathrm{s}^{-}}$ values.

\begin{tabular}{|c|c|c|c|}
\hline \multirow[b]{2}{*}{ Experiments } & \multicolumn{3}{|c|}{ Individual simulation after fixed $\mathrm{K}_{\mathrm{s}}$} \\
\hline & $\begin{array}{c}\text { rs max } \\
\mathbf{g ~ g}^{-1} \mathbf{h}^{-1}\end{array}$ & $\begin{array}{c}\mathrm{K}_{\mathrm{i}} \\
\mathrm{g} \mathrm{L}^{-1}\end{array}$ & $\mathbf{R}^{2}$ \\
\hline Phen-1 & 0.19 & 0.212 & 0.76 \\
\hline Phen-2 & 0.25 & 0.169 & 0.96 \\
\hline Phen-3 & 0.38 & 0.655 & 0.94 \\
\hline Benz-1 & 0.99 & 0.334 & 0.89 \\
\hline Benz-2 & 0.60 & 0.552 & 0.97 \\
\hline Benz-3 & 0.51 & 0.896 & 1.00 \\
\hline
\end{tabular}

In contrast with phenol, these results reveal no dependency increasing of the modeled $r_{S \max }$ with the increasing of initial benzoate concentration was obtained. Due to lower initial biomass $\left(0.48 \mathrm{~g} \mathrm{~L}^{-1}\right)$, maximum specific benzoate consumption rate of Benz-1 was reached with higher value than those of the other batches. This, however, may reflect the overall effective role played by the initial biomass concentration and the initial substrate concentration on the rsmax values. For all variables, good agreement between the kinetic model and experimental data was achieved.

It could be concluded that, conversion of phenol and benzoate by $B$. cepacia G4 can be described by Yano and Koga kinetics under classical batch conditions quite well. It seems evident that the performance of the cells is dependent of the substrate inhibition, adaptation and probably the initial biomass concentration. However, influence of cell adaptation was already stated by Sokot (1987). This was shown by the enzyme regulation. Therefore, it is probable that the cells control their enzyme level, adjusting it to face the current conditions. This corresponds also with the theory of Kovárová-Kovar and Egli (1998), who state that the cells constantly adapt to the environmental conditions by varying their kinetic parameters. 


\section{ACKNOWLEDGEMENTS}

The author thanks Dr. V. Hecht (Divission of Biochemical Engineering, GBF, Braunschweig, Germany) for his profrssional guidance. Sincer thanks are also to Prof. Dr. K. N. Timmis for providing the strain.

\section{REFERENCES}

Allsop, P. J.; Y. Chisit; M. Moo-Young and G. R. Sullivan (1993). Dynamics of phenol degradation by Pseudomonas putida. Biotechnol. Bioeng. 41: $572-580$.

Amorose, I.; R. Connon; H. Garelick; J. L. Alonso and J. M. Carrasco (2000). An assessment of the toxicity of some pesticides and their metabolites affecting a natural aquatic environment using the Microtox TM system. Water Sci. Technol., 42: 19-24.

Ampe, F. and N. D. Lindley (1996). Flux limitations in the ortho pathway of benzoate degradation of Alcaligenes eutrophus: metabolite overflow and induction of the meta pathway at high substrate concentrations. Microbiol. 142: 1807-1817.

Andrews, J. F. (1968). A mathematical model for the continious culture of microorganisms utilizing inhibitory substrates. Biotechnol. Bioeng. 10: 707-723.

Babish, H. and D. L. Davis (1984). Phenol: A review of environmental and health risks. Regulat. Toxicol. Pharmacol., 1: $90 \mathrm{p}$.

Cho, Y-G.; S-K. Rhee and S-T. Lee (2000). Influence of phenol on biodegradation of $p$-nitrophenol by freely suspended and immobilized Nocardioides sp. NSP41. Biodegrad. 11: 21-28.

D. Adamo, P. D.; A. F. Rozich and A. F. Gaudy Jr. (1984). Analysis of growth data with inhibitory carbon sources. Biotechnol. Bioeng. 26: 397-402.

DiBasio, D. H.; H. C. Lim and W. A. Weigand (1981). An experimental investigation of stability and multiplicity of steady states in biological reactor. J. AIChE. 27: 284-290.

Farrell, A. and B. Quilty (1999). Degradation of mono-chlorophenols by a mixed microbial community via a meta-cleavage pathway. Biodegradation, 10: 353-362.

Goudar, C. T.; S. G. Ganji; B. G. Pujar and K. A. Strevett (2000). Substrate inhibition kinetics of phenol biodegradation. Water Environment Research, 72 (1): 50-54.

Haldane, J. B. S. (1930). Enzymes. Longmans, Londen.

Hamzah, R. Y. and B. S. Al-Baharna (1994). Catechol ring cleavage in Pseudomonas cepacia: the simultaneous induction of ortho and meta pathways. Appl. Microbiol. Biotechnol. 41: 250-256.

Han, K. and O. Levenspiel (1988). Extended Monod kinetics for substrate product and cell inhibition. Biotechnol. Bioeng. 32: 430-437.

Harayama, S.; N. Mermod; M. Rekik; P. R. Lehrbach and K. N. Timmis (1987). Roles of the divergent branches of the meta-cleavage pathway in the degreadation of benzoate and substituted benzoates. $J$. Bacteriol. 169: 558-564. 
Hecht, V.; O. Langer and W.-D. Deckwer (2000). Degradation of phenol and benzoic acid in a three-phase fluidized-bed reactor. Biotechnol. Bioeng. 70: 391-399.

Hickey, W. J. and D. D. Focht (1990). Degradation of mono-, di-, and trihalogenated benzoic acids by Pseudomonas aeruginosa JB2. Appl. Environ. Microbiol. 56: 3842-3850.

Jayakumar, S. and H. C. Lim (1989). Multiple steady states of Methylomonas mucosa for continuous production of polysaccharides. J. Biotechnol. 12: 21-36.

Kovárová-Kovar, K. and T. Egli (1998). Growth kinetics of suspended microbial cells: from single-substrate-controlled growth to mixedsubstrate kinetics. Microbiol. Molecul. Biol. Rev. 62: 646-666.

Léonard, D.; C. Ben Youssef; C. Destruhaut; N. D. Lindley and I. Queinnec (1999). Phenol degradation by Ralstonia eutropha: Colorimetric determination of 2-hydroxymuconate semialdehyde accumulation to control feed strategy in fed-batch fermintations. Biotechnol. Bioeng. 65: 407-415.

$\mathrm{Li}, \mathrm{J}-\mathrm{K}$. and A. E. Humphrey (1989). Kinetic and fluorometric behavior of a phenol fermentation. Biotechnol. Lett. 11: 177-182.

Loh, K.-C. and S.-S. Chua (2002). Ortho pathway of benzoate degradation in Pseudomonas putida: induction of meta pathway at high substrate concentrations. Enzym. Microb. Technol. 30: 620-626.

Luong, J. H. T. (1987). Generalization of Monod kinetics for analysis of growth data with substrate inhibition. Biotechnol. Bioeng. 29: 242-248.

Monod, J. (1949). The growth of bacterial cultures. Ann. Rev. Microbiol. 3: 371-394.

Mörsen, A. and H. J. Rehm (1990). Degradation of phenol by a defined mixed culture immobilized by adsorption on activated carbon and sintered glass. Appl. Microbiol. Biotechnol. 33: 206-212.

Nelson, M. J. K.; S. O. Montgomery; E. J. O=Neill and P. H. Pritchard (1986). Aerobic metabolism of trichloroethylene by a bacterial isolate. Appl. Environment. Microbiol. 52: 383-384.

Nelson, M. J. K.; S. O. Montgomery; W. R. Mahaffey and P. H. Pritchard (1987). Biodegradation of trichloroethylene and involvement of an aromatic biodegradative pathway. Appl. Environment. Microbiol. 53: 949-954.

Roels, J. A. (1983). Energetics and kinetics in biotechnology. Elsevier Biomedical Press, Amsterdam.

Salmond, C. V.; R. G. Kroll and I. R. Booth (1984). The effect of food preservatives on $\mathrm{pH}$ homeostasis in Escherichia coli. J. Gen. Microbiol. 130: 2845-2850.

Schröder, M.; C. Müller; C. Poston; W.-D. Deckwer and V. Hecht (1997). Inhibition kinetics of phenol degradation from unstable steady-state data. Biotechnol. Bioeng. 54: 567-576.

Soko $\approx$, W. (1987). Oxidation of an inhibitory substrate by washed cells (oxidation of phenol by Pseudomonas putida). Biotechnol. Bioeng. 30: 921-927. 
Tan, Y.; Z.-X. Wang and K. C. Marshall (1996). Modelling substrate inhibition of microbial growth. Biotechnol. Bioeng. 52: 602-608.

Van der Woude, B. J.; J. C. Gottschal and R. A. Prins (1995). Degradation of 2,5-dichlorobenzoic acid by Pseudomonas aeruginosa JB2 at low oxygen tensions. Biodegradation, 6: 39-46.

Vojta, V.; J. Náhlík; J. Páca and E. Komárková (2002). Development and verification of the control system for fed-batch phenol degradation processes. Chem. Biochem. Eng. Q. 16: 59-67.

Wang, S.-J. and K.-C. Loh (1999). Modelling the role of metabolic intermediate in kinetics of phenol biodegradation. Enzyme and Microbial Technology, 25: 177-184.

Wayman, M. and M. C. Tseng (1976). Inhibition-threshold substrate concentrations. Biotechnol. Bioeng. 18: 383-387.

Yano, T. and S. Koga (1969). Dynamic behaviour of the chemostat subject to substrate inhibition. Biotechnol. Bioeng. 11: 139-153.

$$
\begin{aligned}
& \text { ديناميكية الهنم الحيوى للفينول والبنزوات في نظام الأستزراع الثابت بواسطة } \\
& \text { BURKHOLDERIA CEPACIA G4 بكتيرية }
\end{aligned}
$$

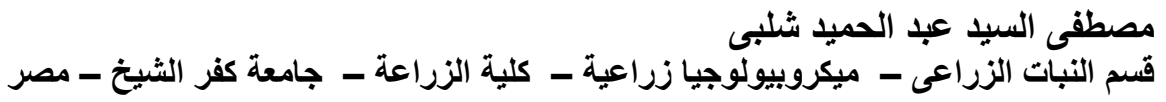

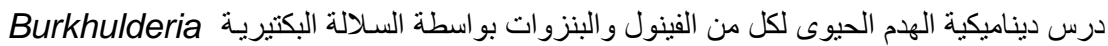

cepacia G4

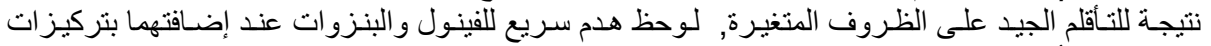

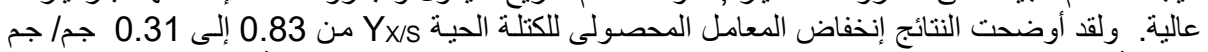

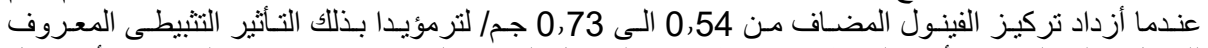

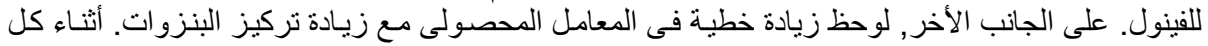

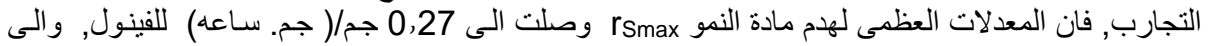

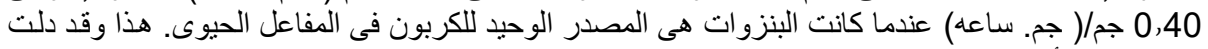

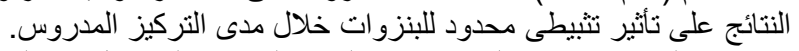

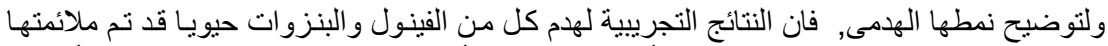

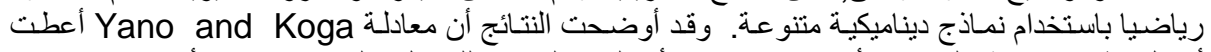

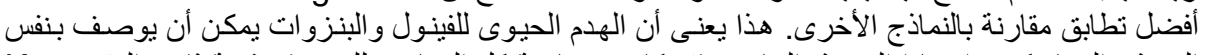

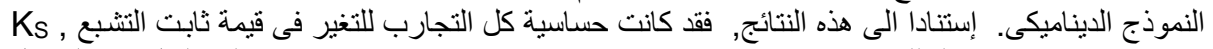

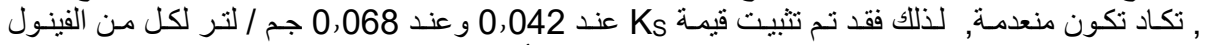

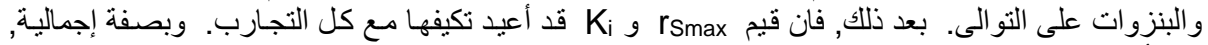

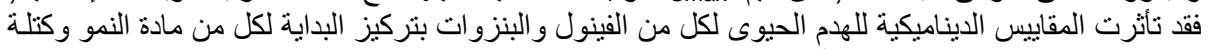

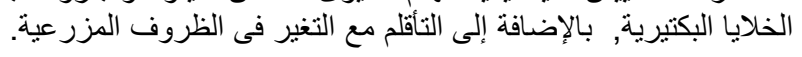


Shalaby, M. E. A.

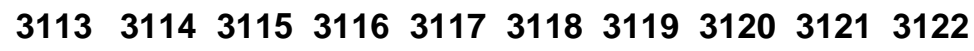

$\begin{array}{lllll}3001 & 3002 & 3003 & 3004 & 3005\end{array}$

30073008300830093010301130123013301430153016

301730183019

3018 